\title{
MEDIASTINAL EMPHYSEMA AND ITS OCCURRENCE IN ARTIFICIAL PNEUMOPERITONEUM
}

\author{
BY \\ C. S. BREATHNACH \\ From the Rialto Chest Hospital, Dublin
}

(RECEIVED FOR PUbliCATION NOVEMBER 2, 1954)

Air may enter the mediastinal fascial planes either by accident or design. The term " pneumomediastinum" should be reserved for the Continental practice of insufflation of air into the mediastinum in contrast radiography (Bariéty, Coury, Mathé, and Abélanet, 1953). The accidental extravasation of air into the mediastinum, or "mediastinal emphysema," is described in this paper, which includes a report of three cases of this condition complicating artificial pneumoperitoneum, and its anatomical basis is reviewed.

Jehn and Nissen (1927) described the first case of mediastinal emphysema complicating artificial pneumoperitoneum, and important contributions to our understanding of the condition were made by Hamman $(1934,1937,1939 a, 1939 b, 1945)$ and the Macklins (1937, 1939, 1943, 1944). Further cases have been described by Banyai and Jurgens (1939), Aslett and Jarman (1945), Simmonds (1946), Morrison (1949), Lemanissier, Breant, and Fourchon (1950), Weiss and Stanley (1951), Small and Fremont (1951), Schwaderer (1951), Towbin (1951), Cohen (1952), Tinker (1953), and Peabody and Buechner (1953). Others have been briefly noted by Clifford-Jones and Macdonald (1943), Anderson and Winn (1945), Keers (1948), Moyer (1949), Stein (1951), and Bobrowitz (1953). In all, 46 cases have been reported.

\section{CASE REPORTS}

CASE 1.-S. O. B., a man aged 28, in January, 1952, as the result of a haemoptysis, was admitted to Rialto Hospital where tubercle bacilli were recovered from the sputum and a chest radiograph showed right apical cavitation with some surrounding infiltration. Following rest and chemotherapy an artificial pneumoperitoneum was induced in August, 1952, and 1,000 ml. of air was given at weekly refills. The usual pressure recordings were $+6 \mathrm{~mm}$. $\mathrm{H}_{2} \mathrm{O}$ before and $+12 \mathrm{~mm}$. $\mathrm{H}_{2} \mathrm{O}$ after.

Three months later, during gastric lavage (five days after a refill), as the tip of the rubber tube lay in the pharynx and the patient tried to swallow it, he experienced nausea, began to retch and developed a sensation of tearing at the lower end of the sternum.
This was quickly followed by subcutaneous emphysema of the neck. The tube was removed, but soon bilateral cervical swellings appeared which obliterated the upper borders of the sternomastoid muscles, and showers of soft crepitations were audible all over the precordium with each cardiac contraction. No injury to the pharyngeal mucosa could be seen. A postero-anterior chest film showed thin, translucent lines beside the right mediastinal and left cardiac borders, and extensive cervical emphysema ; the lateral view revealed a retrosternal collection of air. Symptoms lasted for two days and the signs gradually subsided in 10 days. Refills were discontinued, but little change in the size of the pneumoperitoneum was detectable during the month following the accident.

Case 2.-In L. C., a man aged 22, following mass radiography in February, 1950, a chest film showed bilateral apical tuberculosis with giant cavitation in the right upper lobe; tubercle bacilli were found on direct examination of the sputum. A continuous sanatorium régime from May, 1950, to February, 1953, with three courses of chemotherapy and two threemonth spells of postural recumbency, produced little clinical or radiological improvement.

In February, 1953, an artificial pneumoperitoneum was advised. Induction with the introduction of $600 \mathrm{ml}$. of air (pressure : zero before, $+8 \mathrm{~mm} . \mathrm{H}_{2} \mathrm{O}$ after) was performed at midday, and three hours later, while sitting up in bed, he noticed that his voice sounded hollow. He had some soreness in the throat and was aware of a crackling sensation beneath the skin at the angles of the jaw. The neck and face became swollen with subcutaneous emphysema and soft crepitations synchronous with systole could be heard along the left sternal border and at the apex of the heart. No radiograph was taken. The symptoms disappeared overnight, and the signs during the following three days. Uncomplicated reinduction of the pneumoperitoneum was accomplished one week later, but mediastinal emphysema recurred after one month during which time weekly refills of $1,000 \mathrm{ml}$. of air had been given (pressures : $+8 \mathrm{~mm}$. $\mathrm{H}_{2} \mathrm{O}$ before, $+12 \mathrm{~mm}$. $\mathrm{H}_{2} \mathrm{O}$ after). A second resumption of small refills, $450 \mathrm{ml}$. to $600 \mathrm{ml}$., was uneventful three weeks later, but the measure was abandoned as dangerous.

CASE 3.-K. K., a woman aged 27, had phthisis diagnosed in October, 1949, when a chest film was advised because of inordinate lassitude, but she 
refused to spend more than seven weeks in a sanatorium. In May, 1952, a further film suggested that the disease was still active. Chemotherapy after admission to the Rialto Hospital in January, 1953, was followed by an artificial pneumoperitoneum induced in May, 1953. Refills never exceeded $600 \mathrm{ml}$. and the greatest and usual pressure range was $+4 \mathrm{~mm} . \mathrm{H}_{2} \mathrm{O}$ before and $+8 \mathrm{~mm}$. $\mathrm{H}_{2} \mathrm{O}$ after. A bout of coughing on the day following the eighth refill was accompanied by a sudden sense of discomfort in the chest and neck. Slight dysphagia was experienced, but she was not distressed. On examination cervical emphysema was present but not conspicuous. Cyanosis was absent. Crepitus was palpable in the neck and underneath the mandible, and a systolic crepitant sound was heard all over the heart with greatest intensity at the base. The typical appearance of duplication of the visceral borders by translucent lines was obvious in the postero-anterior chest radiograph. Symptoms were not troublesome after the first day and the signs had cleared by the third day. The pneumoperitoneum was abandoned.

\section{ANATOMICAL CONSIDERATIONS}

\section{Access to THE Mediastinum}

The mediastinum, which Gray (1935) defines as the interval within the thoracic cavity between the two pleural sacs, is bounded by the diaphragm below and by the plane of the thoracic inlet above, through which it is in direct communication with the structures of the neck within the investing layer of the deep cervical fascia, an upward extension of which (known as the "parotid fascia") ensheathes the parotid gland. Direct access into the mediastinum may be had from above through the neck, but inferior entry cannot be direct because of the intervention of the diaphragm. Hence the apertures normally present in the diaphragm are the most probable portals of access and their likelihood of incrimination is intimately associated with their peritoneal relations. These are as fo!lows (Fig. 1):

RETROPERitONEALly.-(1) The "psoas" space behind the medial and lateral arcuate ligaments, (2) aortic opening, (3) lesser crural apertures, and

A. Aorta.
B. Buccinator m.
C. Pericardium.
D. Diaphragm.
E. Pleura.
F. Perivisceral-fascia.
G. Stomach.
I.M.A. Int. mammary artery.
I.V.C. Inf. vena cava.
L. Liver.
O. Oesophagus.
P. Peritoneum.
P.A. Pulmonary artery.
P.V. Pulmonary vein.

KeY to Figs. 1 and 2.

R.S. Rectus $m$. and posterior sheath.

S. Sternum.

S.V.C. Sup. vena cava.

T. Trachea and bronchial tree.

T.A. Transversus abdominis $\mathrm{m}$.

V. Vertebral column.

1. Retro-ligamentous space.

2. Aortic opening.

3. Lesser crural apertures.

4. Posterior deficient area.

5. Inf. vena caval orifice.

6. Openings for minute veins.

7. Anterior deficient area.

8. Oesophageal hiatus.
FIG. 1.-The perivisceral fascia: a sagittal section through the neck and mediastinum, the latter as seen from the left side. (Schema- $\sigma$ tic, after Gray and Marchand.)

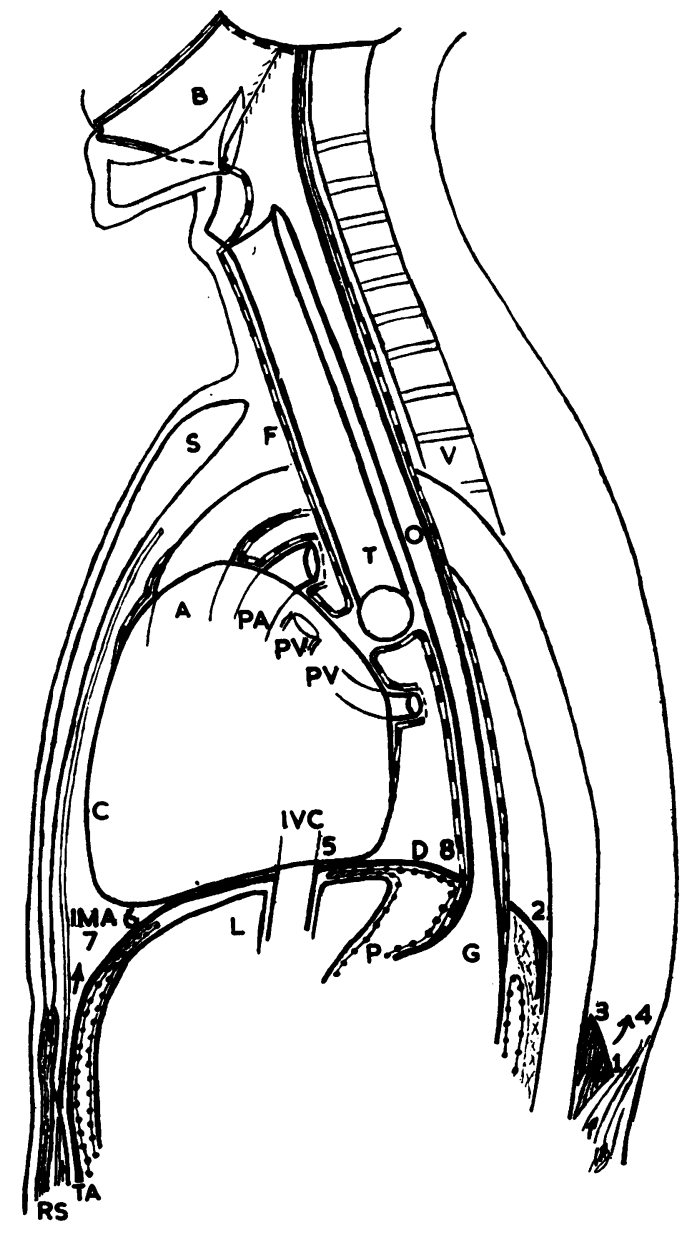

Fig. 2.-The perivisceral fascia: a transverse section through the thorax about the level of the fifth thoracic vertebra. (Schematic after Gray and Marchand.)

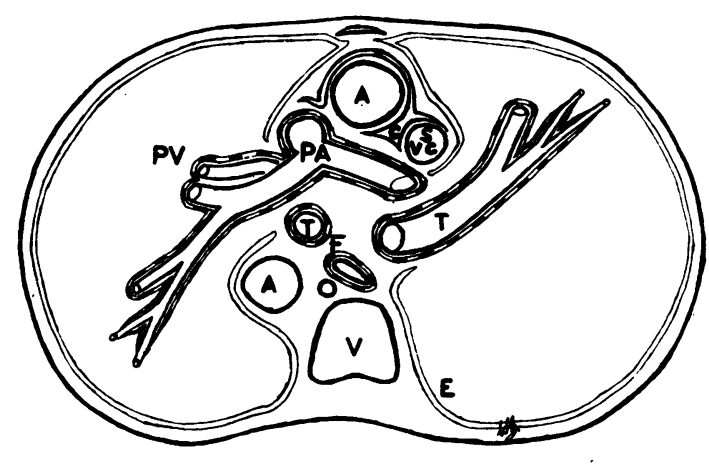

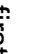


(4) the posterior deficient area close to the arcuate ligaments, probably the site of occurrence of the hiatus of Bochdalek due to defective dorsal closure of the pleuroperitoneal canal (Brown, 1952).

JUXTAPERITONEALLY.-(5) The vena caval quadrilateral opening, the margin of which is adherent to the vessel. The upper layer of the coronary ligament is the nearest peritoneal approach to this sulcus on the "bare area" of the liver in which the vein lies.

Preperitoneally.-(6) Openings for minute veins are frequently seen in the central tendon. However, these are of lesser importance than the continuity of the diaphragm and transversus muscles and posterior rectus sheath with the formation of a single fibromuscular layer as shown by Rives and Baker (1942). The lamellation of the aponeurosis of the internal oblique along the linea semilunaris separates the transversus and rectus muscles and distinguishes this possible route from the one following. (7) The anterior deficient area between the sternal and costal origins which transmits the superior epigastric branch of the internal mammary artery into the rectus sheath. Brown (1952) has shown that this is the site of the rare parasternal hernia, and it is often referred to as the foramen of Morgagni or space of Larrey.

Peritoneally.-(8) Oesophageal: this elliptical hiatus is directly related to the peritoneum which is loosely applied, as Meyer (1950) has noted, because of the mobility of the contiguous viscera and parities, to the abdominal oesophagus in front and on its left side. Harrington (1940) has shown that in as many as one person in three more than one finger can be inserted between the oesophagus and the encircling diaphragm. Here, therefore, a lone lax layer of peritoneum separates the abdominal cavity from the mediastinum.

Within the labyrinth of fascial spaces in the neck and mediastinum Marchand (1951) has demonstrated a perivisceral sheath which encloses the trachea and oesophagus in their entire extent. Above it is attached to the cricoid arch anteriorly, while laterally and dorsally it is continuous with the self-limiting buccopharyngeal aponeurosis. At the tracheal bifurcation, as depicted in Fig. 2, the fascia sweeps anteriorly and becomes continuous with the fibrous pericardium which provides fascial sheaths for the great vessels, the inferior vena cava excepted, but becomes firmly adherent to the serous layer over the ventricles. Here too the right and left bronchi are invested by lateral prolongations which, like the investments of the pulmonary vessels derived from the pericardium, are readily separated in their extrapulmonary extent but become progressively more adherent to the bronchi and the vessels as they branch until separation becomes wellnigh impossible. The oesophageal part continues downwards through the diaphragm to blend eventually with the subserous coat of the stomach. This fascial space, enclosed to its extremities, lies within and yet is outside the mediastinum (Figs. 1 and 2).

\section{AIR ROUTES}

The most important single clinical feature is the division of the mediastinum into two distinct compartments by the perivisceral fascia, and the air routes must be considered in relation to this simple sheath.

\section{Enclosed Penetration of Air beneath the Perivisceral Fascia}

Alveolar rupture by markedly increased intrapulmonary pressure with retrograde dissection through the peribronchial or perivascular ramifications (Fig. 2) causes the true spontaneous emphysema due to $(a)$ obstruction of expiration in the upper respiratory tract most frequently at the glottis, or $(b)$ segmental or lobar over-distension behind an endobronchial valvular mechanism such as that described by Coryllos (1936) in pulmonary tuberculosis, in artificial pneumothorax or pneumoperitoneum, or in healthy persons during violent coughing or straining.

Possibly there may be a communication between the two potential spaces where the perivisceral fascia and peritoneum lie in apposition along the abdominal oesophagus (Fig. 1).

A " limited" perforation of the trachea, bronchus, pharynx, or oesophagus into the fascial envelope may occur $(a)$ from within outwards by a sharp foreign body, or $(b)$ by an external wound in the manner postulated by Marchand (1951).

\section{Open EXtra-PERIVISCERAL EXTRAVASATION INTO THE "FreE" SPACES}

Air may enter through the buccal mucous membrane $(a)$ as considered likely by Linehan (1950) in three cases of measles, mimicking the mechanism of $(b)$ autemphysesis in the malingerer described by Reading (1950).

It may be of local origin or by downward spread from deliberate or accidental wounds involving the deep cervical fascial planes.

"Complete" perforation of the trachea, bronchus, pharynx, or oesophagus may occur through the perivisceral fascia, or perforation of herniated 
bowel from within or without as in the "limited" variety. The commonest cause is probably tracheotomy and so it is most frequently seen in children.

Air may enter directly from the adjacent extrapleural fascial planes during pneumotherapeutic procedures or following thoracic surgery, or from a preperitoneal aerocele (see Fig. 1, A, x). Air injected (a) retromuscularly, between the transversus muscle and transversalis fascia, may pass through the openings for minute veins $(A, 6)$, or (b) intermuscularly, either into the plane between the transversus and internal oblique muscles which is confluent with the supradiaphragmatic planes including the mediastinum, or into the rectus sheath and so through the anterior deficient area (A, 7).

Air may also enter from the retroperitoneal spaces-from a local source, from air injected into the mesentery, or through these tissues from a pneumoperitoneum $(\mathrm{A}, 1-4,8)$, or from the peritoneal cavity indirectly or directly by rupture of an unsupported peritoneal pane, probably at the exposed oesophageal ellipse rather than at the vena caval orifice $(A ; 5,8)$.

\section{Combined SPREAd InSIDE and OUTSIDE THE Perivisceral Fascia}

Air may rupture through the restraining membrane by the enclosed type in an attempt to free itself, or air may spread coincidentally both inside and outside by independent mechanisms, spontaneously, during oropharyngeal or cervical surgery, or in the course of artificial pneumoperitoneum. In wounds perforating the trachea, bronchus, or oesophagus and the surrounding sheath air may disgorge itself into either or both compartments depending on the valvular artefacts produced by the injury.

\section{The Pathway Problem in Artificial PNEUMOPERITONEUM}

Enclosed mediastinal emphysema is extremely rare in artificial pneumoperitoneum. The open type, on the other hand, is not so infrequent although it is relatively less common since the subcostal and para-umbilical sites of insufflation have become obsolete $(A, 6,7)$.

The mechanism in true pneumoperitoneum is not certain. Small and Fremont's (1951) surmise, following Hamman (1939b), of a retroperitoneal route related somewhat to experiments on air-flow in the opposite direction reported by Jehn and Nissen (1927), by Joannides and Tsoulos (1930), and by Macklin (1939) neglects to explain satis- factorily the process by which air passes the broad-buttressed posterior peritoneal barrier $\overline{0}$ Pneumothorax rather than emphysema is more likely to follow faults in coelomic division which leave intercavitary channels (Breathnach, 1953); $;$ the hiatus of Bochdalek is therefore an unlikely avenue (A, 1-4). A more likely explanation is ${ }^{\infty}$ that air penetrates the peritoneum where it iș least protected, namely at the oesophageal orifice $=$ (A, 8). Perforation may occur early, even at the $e^{\omega}$ induction of pneumoperitoneum, when the sac is particularly tenuous; conversely, if the tensile. strength is considerable, the breach may be delayed $\overrightarrow{0}$ indefinitely until some additive action greatly en- -

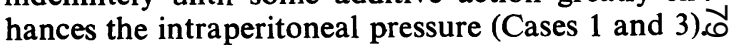
It is possible too that fibrous healing may prevent? or delay recurrence in the event of re-induction(Case 2). This hypothesis accords with the appear ance of emphysema unassociated with either in duction or refill of pneumoperitoneum, with its 5 more frequent occurrence at refill than at induc $\vec{r}$ tion, and with the unpredictability of recurrencer in the event of re-induction.

\section{CLASSIFICATION}

Air entering the inner confined space of theo cervico-mediast:nal perivisceral plane described by Marchand (1951) is impounded and can only: escape by fascial rupture, and its rising volume ans pressure compress the contained structures with increasing functional impairment-the "malig? nant "type. Infiltration of air outside the rigid boundaries of the perivisceral fascia is not nearlyo so noxious because of its freedom to diffuse widely and the greater capacity of the mediastinum andb neck to accommodate the escaping gas. The rela? tive benignity of this exterior extravasation is particularly noticeable where only a finite quantity of air is available for escape, as is the case ing pneumoperitoneum.

There are thus three types of mediastinal emphy음 sema, namely the enclosed or malignant, the free or benign, and a combination of these.

\section{CLINICAL FEATURES}

\section{Enclosed or Malignant Mediastinal EMPHYSEMA}

PredisPosing FACTORS.-Expiratory obstruction? without equal inspiratory impairment, such aso may follow valvular endobronchial occlusion, arising especially in the course of pulmonar ${ }_{B}^{D}$ tuberculosis or its collapse therapy, is one factor $\overrightarrow{\mathbb{D}}$ Upper respiratory obstruction, particularly forceff expiration against a closed glottis, notably in the 
bearing-down efforts of parturition, causes alveolar inflation and possible consequent rupture into the perivisceral space, which may also be laid open as the result of traumatic perforation, from within or without, of the mediastinal air-containing viscera. Pleural as well as perivisceral rupture may result from alveolar distension, and not infrequently the clinical picture is complicated by a spontaneous pneumothorax.

Symptoms.-The insidious onset of unexplained respiratory distress, or its progression in spite of adequate treatment of a spontaneous pneumothorax, in the presence of one of the above aetiological factors must always arouse suspicion. A majority of patients complain of pain, not unlike angina, of sudden onset, and partially relieved by rest, occasionally accompanied by a sense of tearing in the chest. Early slight shortness of breath increases slowly until it is unbearable and the patient becomes anxious and restless. An irritant cough may develop and soon deglutition becomes difficult.

SignS.-Subcutaneous emphysema is not discernible, but a deepening cyanosis corresponds with the increasing dyspnoea. Hamman's sign (1939b), a systolic crunch due possibly to compression and displacement of the perivascular air, is heard over the precordium, in some cases without the aid of a stethoscope. Hoffman, Pobirs, and Merliss (1943), Fagin and Schwab (1946), and Small and Fremont (1951) have suggested using a phonocardiogram to differentiate this sign from the pericardial friction rub of a subserous infarction with which it may be confused. In the interpretation of the electrocardiographic tracings, which are of greater diagnostic value, the changes consequent upon the axial displacement of the heart by the subdiaphragmatic air, flattening of the $\mathrm{S}-\mathrm{T}$ segment in lead II and a conspicuous $\mathrm{Q}$ followed by a small $R$ and inverted $T$ in lead III (Benatt and Berg, 1945) should not be forgotten in the rare cases of malignant emphysema complicating artificial pneumoperitoneum. Coronary thrombosis, however, seldom causes difficulty in differential diagnosis.

Radiology.-Fine translucent lines beside the oesophagus and great vessels in the thorax may be seen in the postero-anterior and lateral films.

Prognosis.-Spontaneous rupture or remission by stopping the causative valvular action is possible, but a fatal outcome is not unlikely if the perivisceral tension is not relieved (Hamman, 1945).
TreatMent.-Incision of the perivisceral fascia, which is most accessible pretracheally above the thyroid isthmus, affords relief. Removal of the pneumoperitoneum, if present, makes no difference.

\section{Free or Benign Mediastinal Emphysema}

Predisposing Factors.-Benign emphysema may be seen in oropharyngeal, cervical, or thoracic surgery, in penetrating wounds of the neck and chest, and in artificial pneumothorax, especially after thoracoscopy, and artificial pneumoperitoneum.

Symptoms.-The patient's first complaint is of substernal discomfort rather than of pain. $\mathrm{He}$ may complain of sudden swelling of the neck, of sore throat with slight dysphagia, or of a crunching sensation in one or both ears on mastication. Anxiety is not unduly prominent and cardiorespiratory distress is conspicuously absent.

Signs.-Cervical emphysema, often clearly visible, can be appreciated readily by palpation in nearly every case. Very gentle pressure in the sterno-clavicular angle will reveal the crepitus when only small quantities of air are present. Mumps may be simulated by the infiltration of air into the parotid fascia. Cyanosis is never prominent. Crackling crepitations, resembling pericardial friction but seldom as harsh as the systolic crunch of Hamman (1939b), are audible over the precordium with maximum intensity most commonly at the apex. This systolic sound, which is unaffected by respiratory inhibition, is probably produced by the inrush of air into the space made by contraction of the ventricles; a gentler rustle may occur during diastole, giving a double murmur. Stern, quoted by Graebner (1939), likened the turbulence of air in the mediastinum to the crushing of cellophane in the hand.

RADIOLOGY.-In the postero-anterior film thin zones of transparency between the pleura and heart and oesophagus may be detected. The lateral view, generally agreed to be the most. revealing (Evans and Smalldon, 1950), shows retrosternal concentration of the air particularly in the superior mediastinum which may, in doubtful cases, be accentuated by Littmann's (1946) manœuvre of taking the lateral radiograph with the patient supine.

Prognosis.-The outlook is uniformly good, particularly where the volume of air available for infiltration is limited, as it is in artificial pneumoperitoneum, and complete symptomatic relief is the rule, of ten within three to seven days. 
Treatment.-Treatment is expectant. A word of reassurance is appreciated, sedation is seldom required, and aspiration of the abdominal air, when present, is not essential.

\section{Combined Mediastinal Emphysema}

Predisposing Factors.-Traumatic or spontaneous rupture of the perivisceral fascia may cause combined emphysema, which may also occur by independent mechanisms, for example, in respiratory obstruction during oropharyngeal or cervical surgery-e.g., great excitement in the second stage of anaesthesia at tonsillectomy, traumatic recurrent laryngeal paralysis at thyroidectomy, or during artificial pneumoperitoneum.

SYMPTOMS.-A sudden relief of the symptoms of malignant emphysema almost certainly indicates that the air has ruptured throughout the perivisceral fascia. If the two conditions appear concomitantly the symptoms of the benign variety usually appear first, to be followed by increasing distress and cyanosis.

\section{CONCLUSION}

Mediastinal emphysema, of which there are two major types and a third lesser one, is an infrequent complication of artificial pneumoperitoneum, especially in its malignant form. The benign variant, when it is not the result of faulty technique in insufflation, occurs through a diaphragmatic defect, probably acquired and placed at the oesophageal hiatus.

\section{SUMmary}

Mediastinal emphysema is defined, the history of its appearance as a complication in artificial pneumoperitoneum is outlined, and three cases are reported.

The anatomy and applied anatomy, the mechanisms of production and modes of presentation are discussed, and a new classification, based on the study of the perivisceral fascia in the mediastinum by Marchand (1951), is advanced.

In the overwhelming majority of cases in which this complication of artificial pneumoperitoneum appears, the emphysema occurs in the free fascial spaces of the neck and mediastinum and is seldom of serious import.

Misplaced air may readily enter the mediastinum, but rupture of a true pneumoperitoneum is restricted to an acquired para-oesophageal weakness.
A descriptive clinical outline in accordance with $\overrightarrow{\vec{s}}$ the proposed classification into three types-en-o closed or malignant, free or benign, and combinedo emphysema-with brief therapeutic recommenda $\overline{\bar{n}}$ tions, is included.

For permission to publish and for his unfailing interest and instructive criticism in the preparation of̣ this paper, I am very grateful to Dr. John Duffy $\vec{\overrightarrow{ }}$ Resident Medical Superintendent. Dr. Neville Oswalow leaves me deeply indebted to him for his advice on pruning. To my colleagues, Drs. T. F. Ryan and $M \times$ Herlihy with whom I shared the care of these patients $\overrightarrow{0}$ for their kind co-operation, and to the Misses O'Sullivan and Breathnach for their diligence in the prepara $v$ tion of the typescript, I am very thankful.

\section{REFERENCES}

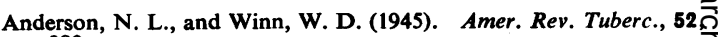
380

Aslett, E., and Jarman, T. F. (1945). Lancet, 1, 304.

Banyai, A. L., and Jurgens, G. H. (1939). J. thorac. Surg., 8, 329. Bariéty, M., Coury, C., Mathé, P., and Abélanet, R. (1953). Sem of Hôp. Paris, 29, 1129.

Benatt, A. J and Berg. W. F. (1945). Amer. Heart J., 30, 579.

Bobrowitz, I. D. (1953). Dis. Chest, $24,82$.

Bobrowitz, I. D. (1953). J. Irish med. Ass., 33, 14.

Brown, R. W. (1952). Thorax, 7, 266.

Clifford-Jones, E., and Macdonald, N. (1943). Tubercle, $24,97$.

Cohen, R. C. (1952). Ibid., 33, 312 .

Coryllos, P. N. (1936). Amer. Rev. Tuberc., 33, 639.

Evans, J. A., and Smalldon, T. R. (1950). Amer. J. Roentgenol., 64 , 375 .

Fagin, I. D., and Schwab, E. H. (1946). Ann. intern. Med., 24, 1052.

Fagin, I. D., and Schwab, E. H. (1946). Ann. intern. Med., 24,
Graebner, H. (1939). Arch. Otolaryngol., Chicago, 29, 446

Gray, H. (1935). Anatomy, Descriptive and Applied, 26th ed., ed Johnston, T. B. Longmans, Green and Co., London.

Hamman, L. (1934). Ann. intern. Med., 8, 417.

(1937). Trans. Ass. Amer. Phys., 52, 311

(1939a). Ann. intern. Med., 13, 923.

(1939b). Bull. Johns Hopk. Hosp., 64, 1. (1945). J. Amer. med. Ass., 128, 1.

Harrington, S. W. (1940). Amer. J. Surg., 50, 377.

Hoffman, A. M., Pobirs, F. W., and Merliss, R. (1943). Amer Heart J., 26, 686.

Jehn, W., and Nissen, R. (1927). Dtsch. Z. Chir., $206,221$.

Joannides, M., and Tsoulos, G. D. (1930). Arch. Surg., Chicago 21, 333.

Keers, R. Y. (1948). Brit. J. Tuberc., 42, 58.
Lemanissier, A. F., Breant, J., and Fourchon, J. (1950). Poumon, 6马 543.

Linehan, J. J. (1950). Brit. med. J., $2,762$.

Littmann, D. (1946). Amer. J. med. Sci., $212,682$.

Macklin, C. C. (1937). Canad. med. Ass. J., 36, 414.

Macklin, C. C. (1937). Canad. med. Ass. J., 36, 414. Gerbert M. Evans, p. 33. Univ. Calif. Press, Berkeley, Calif. N

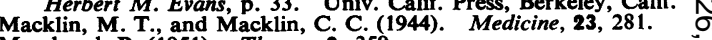

Marchand, P. (1951). Thorax, 6, 359.

Meyer, H. W. (1950). J. thorac. Surg., 20, 235

Morrison, J. B. (1949). Brit. J. Tuberc., 43, 18

Moyer, R. E. (1949). Dis. Chest, 15, 43. 68,775 .

Reading, P. (1950). Brit. med. J., 1, 105.

Rives, J. D., and Baker, D. D. (1942). Ann. Surg., 115, 745.

Schwaderer, A. (1951). Tuberkuloseartz, 5, 599.

Schwaderer, A. (1951). Tuberkuloseartz, 5, 599.

Small, M. J., and Fremont, R. E. (1951). Amer. Rev. Tuberc., 63, 591:

Stein, H. F. (1951). Ibid., 64, 653.

Tinker, C. M. (1953). Brit. J. Tuberc., 47, 46.

Towbin, M. N. (1951). Ann. intern. Med., 35, 555

Weiss, W., and Stanley, C. O. (1951). J. Philad. gen. Hosp., 2, 13.

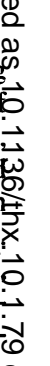

